\title{
Clinical Correlates of Benefit From Radium-223 Therapy in Metastatic Castration Resistant Prostate Cancer
}

\author{
Ajjai Alva, ${ }^{1 *}$ Luke Nordquist, ${ }^{2}$ Stephanie Daignault, ${ }^{1}$ Saby George, ${ }^{3}$ Jorge Ramos, ${ }^{4}$ \\ Costantine Albany, ${ }^{5}$ Sudhir Isharwal, ${ }^{2}$ Matthew McDonald, ${ }^{2}$ Gregory Campbell, ${ }^{1}$ \\ Pongwut Danchaivijitr, ${ }^{3}$ Sarah Yentz, ${ }^{1}$ Aseem Anand, ${ }^{6}$ and Evan Y. Yu ${ }^{4}$ \\ 'Division of Hematology/Oncology, University of Michigan, Ann Arbor, Michigan \\ ${ }^{2}$ Urology Cancer Center and GU Research Network, Omaha, Nebraska \\ ${ }^{3}$ Roswell Park Cancer Institute, Buffalo, New York \\ ${ }^{4}$ Fred Hutchinson Cancer Research Center, Seattle, Washington \\ ${ }^{5}$ Indiana University Melvin and Bren Simon Cancer Center, Indianapolis, Indiana \\ ${ }^{6}$ Department of Translational Medicine, Urological Cancer, Lund University, Lund, Sweden
}

\begin{abstract}
BACKGROUND. We sought to identify potential clinical variables associated with outcomes after radium-223 therapy in routine practice.

METHODS. Consecutive non-trial mCRPC patients who received $\geq 1$ dose of radium dichloride-223 at four academic and one community urology-specific cancer centers from May 2013 to June 2014 were retrospectively identified. Association of baseline and on-therapy clinical variables with number of radium doses received and clinical outcomes including overall survival were analyzed using chi-square statistics, cox proportional hazards, and Kaplan-Meier methods. Bone Scan Index (BSI) was derived from available bone scans using EXINI software.

RESULTS. One hundred and forty-five patients were included. Radium-223 was administered for six cycles in 74 patients (51\%). One-year survival in this heavily pre-treated population was $64 \%$ (95\%CI: $54-73 \%$ ). In univariate and multivariate analysis, survival was highly associated with receiving all six doses of Radium-223. Receipt of six doses was associated with ECOG PS of 0-1, lower baseline PSA \& pain level, no prior abiraterone/ enzalutamide, $<5$ BSI value, and normal alkaline phosphatase. In patients who reported baseline pain $(n=72)$, pain declined in $51 \%$ after one dose and increased in $7 \%$. PSA declined $\geq 50 \%$ in $16 \%(18 / 110)$. Alkaline phosphatase declined $\geq 25 \%$ in $48 \%(33 / 69)$ and $\geq 50 \%$ in $16 /$ 69 patients. BSI declined in $17(68 \%)$ of the 25 patients who had bone scan available at treatment follow-up. Grade $\geq 3$ neutropenia, anemia, and thrombocytopenia occurred in $4 \%$ $(\mathrm{n}=114), 4 \%(\mathrm{n}=125)$, and $5 \%(\mathrm{n}=123)$, respectively.

CONCLUSIONS. Patients earlier in their disease course with $<5$ BSI, low pain score, and good ECOG performance status are optimal candidates for radium-223. Radium-223 therapy is well tolerated with most patients reporting declines in pain scores and BSI. 77: 479-488, 2017. (C) 2016 Wiley Periodicals, Inc
\end{abstract}

KEY WORDS: $\quad$ Bone Scan Index; outcomes; variables

\section{INTRODUCTION}

Metastatic CRPC represents the lethal phenotype of prostate cancer and will cause an estimated 27,540 deaths in 2015 in the United States [1]. Breakthroughs in our understanding of the castration-resistance phenotype of prostate cancer have resulted in several novel
Grant sponsor: Bayer Pharmaceuticals.

${ }^{*}$ Correspondence to: Ajjai Alva, MD, 7310 Cancer Center, University of Michigan, 1500 E Medical Center Drive, Ann Arbor, MI 48109

E-mail: ajjai@med.umich.edu

Received 1 September 2016; Accepted 16 November 2016 DOI 10.1002/pros.23286

Published online 19 December 2016 in Wiley Online Library (wileyonlinelibrary.com). 
agents demonstrating clinical benefits including improved survival [2]. These novel agents include cytotoxic chemotherapy (docetaxel [3,4], cabazitaxel [5]), androgen signaling inhibitors (abiraterone [6,7], enzalutamide [8,9]), immunotherapy (sipuleucel-T [10]), and uniquely, a bone targeted agent, radium-223 [11].

Radium-223 is an intravenously administered bone-seeking radiopharmaceutical emitting alpha-radiation with short tissue penetration depth (2-10 cells deep or $<100$ microns) resulting in minimal toxicity to bone marrow [12,13]. It is distinctly different from samarium-153 ethylene diamine tetramethylene phosphonate or strontium-89 which are palliative in intent and confer significant risk of myelosuppression. Radium-223 was tested in several early trials in CRPC patients with painful bone metastases [13-16]. A single-infusion study of radium-223 with doses ranging from 5 to $100 \mathrm{kbq} / \mathrm{kg}$ demonstrated declines in self-reported pain scores (Visual Analog Scale) and analgesic use as classified by the WHO ladder scale $[15,17]$. A phase 2 double blind trial randomized 122 patients to three different dose levels of radium$223(25,50$, and $80 \mathrm{kBq} / \mathrm{kg})$ given every 6 weeks [18]. Only a minority of patients experienced PSA declines by $50 \%$ or greater $(6 \%$ in the $50-\mathrm{kBq} / \mathrm{kg}$ dose group). A $\geq 50 \%$ decrease in bone alkaline phosphatase (ALP) level was noted in substantially more patients $(67 \%$ at the $50-\mathrm{kBq} / \mathrm{kg}$ dose level). Therapy was well tolerated with few major toxicities at all dose levels.

Subsequently, radium-223 was evaluated in the randomized phase 3 ALSYMPCA trial, in which 921 CRPC patients with $\geq 2$ symptomatic bone-only metastases, either post-docetaxel or declined/ineligible for docetaxel, were treated with either $50 \mathrm{kBq} / \mathrm{kg}$ radium-223 (given intravenously every 4 weeks for up to six cycles) or placebo (2:1 randomization) in addition to best standard of care (excluding cytotoxic chemotherapy). Stratification was by prior docetaxel use $(57 \%$ had prior docetaxel), ALP level, and bisphosphonate use. Radium-223 significantly improved the primary end-point of OS (HR 0.695, 95\%CI $0.552-0.875, P=0.002$ ). Median OS was 14 months with radium-223 and 11.2 months with placebo. The trial confirmed the tolerable safety profile with radium, the most common adverse effects being gastrointestinal toxicities though serious events were similar in both arms (grade $3 / 41 \%$ with radium vs. $1 \%$ with placebo) and bone pain. Importantly, for this patient population with implications for future explorations of concurrent or sequential cytotoxic chemotherapy, grades 3 and 4 hematological toxicity was uncommon (anemia 11\%, neutropenia in $2 \%$, and thrombocytopenia in $4 \%$ ) in the radium arm. Median time to first symptomatic SRE was significantly longer in the radium group (15.6 months vs. 9.8 months, HR
$0.66,95 \%$ CI $0.52-0.83, P=0.00037$ ) [19]. However, no imaging was mandated in the trial and details of prior docetaxel cumulative dose were not tracked. In a planned subgroup analysis, the survival benefit was maintained irrespective of prior docetaxel use albeit with a higher frequency of grade $\geq 3$ thrombocytopenia with radium in docetaxel treated patients (9\% vs. $3 \%$ placebo) compared to docetaxel-naive patients ( $3 \%$ vs. $1 \%$ placebo) $[20]$.

Radium-223 represents a first in class therapeutic agent in CRPC with an overall survival benefit as monotherapy and an intriguing mode of action different from chemotherapy and androgen signaling inhibitors with a relatively benign and non-overlapping toxicity profile to those other classes. The demonstrated overall survival benefit led to regulatory approval of radium-223 by the FDA in 2013 for treatment of metastatic CRPC [21]. Major challenges in clinical practice with radium-223 include the lack of reliable biomarkers to predict benefit in individual patients or discern benefit during radium-223 therapy, and the optimal timing of radium in CRPC patients' clinical course.

Therefore, we sought to characterize the benefit of radium-223 use in routine clinical practice in a multicenter retrospective study and assess the clinical utility of standard blood-based and imaging biomarkers.

\section{METHODS}

\section{Study Design}

The objectives of the retrospective study were to identify covariates and biomarkers associated with radium-223 use. Consecutive non-trial mCRPC patients who received $\geq 1$ dose of radium dichloride223 at four academic and one community urologic oncology specific cancer centers from May 2013 to June 2014 were included. CRPC was defined as patients who had failed androgen deprivation therapy and had been clinically documented to have biochemical and/or radiological progression despite castrate level of serum testosterone $(<50 \mathrm{ng} / \mathrm{dl})$. We collected available baseline, on-treatment and post-radium-223 data including the prior treatment history, ECOG performance score, VAS, analgesic use at baseline, Prostate Specific Antigen (PSA), ALP, and available bone scan images. The study was approved by the Institutional Review Boards at the participating sites.

Automated BSI analysis: commercially available EXINIBone version 2, developed by EXINI Diagnostics $A B$, was used to analyze the available bone scans and to generate automated BSI. The methodology of the automated platform has been described previously [22]. 
TABLE I. Baseline Demographics and Clinical Characteristics

\begin{tabular}{|c|c|}
\hline Variable & Total, $\mathrm{N}=144$ \\
\hline Mean age $(\min , \max )$ in years & $71.8(46.1,92.2)$ \\
\hline \multicolumn{2}{|l|}{ Race } \\
\hline Caucasian & $128(88.9 \%)$ \\
\hline African-American & $8(5.6 \%)$ \\
\hline Asian & $3(2.1 \%)$ \\
\hline Other & $5(3.5 \%)$ \\
\hline \multicolumn{2}{|l|}{ Study site } \\
\hline Fred Hutch & $22(15.3 \%)$ \\
\hline Indiana university & $14(9.7 \%)$ \\
\hline Roswell park cancer center & $36(25.0 \%)$ \\
\hline University of Michigan cancer center & $31(21.5 \%)$ \\
\hline Urology cancer center in Omaha, NE & $41(28.5 \%)$ \\
\hline \multicolumn{2}{|l|}{$\begin{array}{l}\text { ECOG performance status (PS) at } \\
\text { baseline }\end{array}$} \\
\hline 0 & $29(20.9 \%)$ \\
\hline 1 & $82(59.0 \%)$ \\
\hline 2 & $22(15.8 \%)$ \\
\hline 3 & $6(4.3 \%)$ \\
\hline $\begin{array}{l}\text { Mean body mass index in } \mathrm{kg} / \mathrm{m}^{2} \text { ( } \mathrm{min} \text {, } \\
\text { max) }\end{array}$ & $29.2(19.4,45.8)$ \\
\hline Mean height in $\mathrm{cm}(\min , \max )$ & $177(156.9,195.6)$ \\
\hline \multicolumn{2}{|l|}{ Gleason sum } \\
\hline $5-6$ & $11(7.6 \%)$ \\
\hline 7 & $35(24.3 \%)$ \\
\hline 8 & $21(14.6 \%)$ \\
\hline 9 & $60(41.7 \%)$ \\
\hline 10 & $4(2.8 \%)$ \\
\hline Unknown & $13(9.0 \%)$ \\
\hline Prior prostatectomy & $57(39.6 \%)$ \\
\hline Prior definitive radiation therapy & $27(18.8 \%)$ \\
\hline Prior salvage radiation therapy & $29(20.1 \%)$ \\
\hline Prior palliative radiation therapy & $57(39.5 \%)$ \\
\hline LHRH agonist or antagonist therapy & $92(63.9 \%)$ \\
\hline $\begin{array}{l}\text { Prior antiandrogen (e.g., bicalutamide) } \\
\text { for metastatic disease }\end{array}$ & $54(37.5 \%)$ \\
\hline \multicolumn{2}{|l|}{$\begin{array}{l}\text { Prior androgen signaling inhibitor } \\
\text { therapy }\end{array}$} \\
\hline Abiraterone acetate only & $34(23.6 \%)$ \\
\hline Enzalutamide only & $5(3.5 \%)$ \\
\hline $\begin{array}{l}\text { Both abiraterone acetate and } \\
\text { enzalutamide }\end{array}$ & $28(19.4 \%)$ \\
\hline \multicolumn{2}{|l|}{ Prior chemotherapy } \\
\hline Docetaxel/cabazitaxel chemotherapy & $76(52.8 \%)$ \\
\hline Other chemotherapy & $4(2.8 \%)$ \\
\hline \multicolumn{2}{|l|}{ Concurrent with radium-223 } \\
\hline Abiraterone & $29(20.1 \%)$ \\
\hline Enzalutamide & $28(19.4 \%)$ \\
\hline \multicolumn{2}{|l|}{ WHO pain ladder scale at baseline } \\
\hline 1 & $78(54.2 \%)$ \\
\hline 2 & $30(20.8 \%)$ \\
\hline 3 & $11(7.6 \%)$ \\
\hline Missing & $25(17.4 \%)$ \\
\hline Analgesic use at baseline: Narcotics & $58(40.3 \%)$ \\
\hline
\end{tabular}

(Continued)
TABLE I. Continued.

\begin{tabular}{lc}
\hline Variable & Total, N=144 \\
\hline Bone modifying drug use at baseline & $48(33.3 \%)$ \\
Number of radium doses & \\
1 & $15(10.4 \%)$ \\
2 & $24(16.7 \%)$ \\
3 & $12(8.3 \%)$ \\
4 & $12(8.3 \%)$ \\
5 & $7(4.9 \%)$ \\
6 & $74(51.4 \%)$ \\
\hline
\end{tabular}

\section{Statistical Plan}

Baseline data are described. Cox proportional hazards models are used to determine prognostic associations of baseline covariates with overall survival. Multivariable cox models were initially done using complete cases, patients without any missing baseline covariates. This model had a limited set of the data $(<50 \%$ of cases) and therefore multiple imputation was used to impute all missing baseline covariates. Five datasets were imputed and the average of the imputed values for each patient and variable were used as a final dataset. Cox models were repeated (univariate and multivariable) on the multiple imputed dataset and are presented in Table III. Overall survival Cox models for variables from during treatment used data provided only and were not used in the multivariable model. Kaplan-Meier plots are provided by prior treatment and baseline BSI.

Analysis of patient characteristics including baseline covariates and treatment outcomes are described using descriptive statistics classification into the number of Radium-223 treatments given. The association between the number of Radium-223 treatments and the continuous covariates using the ANOVA F-test for presented means or Kruskal-Wallis test for presented medians. Categorical covariates associations were analyzed using Jonckheere-Terpstra test. Additionally, baseline BSI was categorized into $<5$ and $\geq 5$. The overall survival Kaplan-Meier plot is presented.

\section{RESULTS}

One hundred and forty-four patients were included with a mean age of 72 years (Table I). Nearly $70 \%$ had Gleason 8 or greater in their pathology denoting aggressive pathology. Nearly $80 \%$ had ECOG performance score of 0 or 1 . Almost half $(46.5 \%)$ had prior abiraterone acetate/enzalutamide/both, 20\% each had concurrent abiraterone or enzalutamide and $53 \%$ 
TABLE II. Hematologic Toxicity by Grade and Prior Therapy

\begin{tabular}{|c|c|c|c|c|c|c|c|c|c|}
\hline \multirow[b]{2}{*}{ Prior therapy } & \multicolumn{3}{|c|}{ Neutropenia $(\mathrm{N}=115)$} & \multicolumn{3}{|c|}{ Anemia $(\mathrm{N}=126)$} & \multicolumn{3}{|c|}{ Thrombocytopenia $(\mathrm{N}=124)$} \\
\hline & Grade 0 & $1 / 2$ & $3 / 4$ & 0 & $1 / 2$ & $3 / 4$ & 0 & $1 / 2$ & $3 / 4$ \\
\hline None & $33(87 \%)$ & $4(11 \%)$ & $1(3 \%)$ & $5(12 \%)$ & $35(85 \%)$ & $1(2 \%)$ & $22(54 \%)$ & $16(39 \%)$ & $3(7 \%)$ \\
\hline AA/enza & $12(86 \%)$ & $1(7 \%)$ & $1(7 \%)$ & $1(6 \%)$ & $15(94 \%)$ & $0(0 \%)$ & $9(60 \%)$ & $6(40 \%)$ & $0(0 \%)$ \\
\hline Chemo & $24(89 \%)$ & $2(7 \%)$ & $1(4 \%)$ & $1(4 \%)$ & $23(85 \%)$ & $3(11 \%)$ & $18(67 \%)$ & $7(26 \%)$ & $2(7 \%)$ \\
\hline Chemo + AA/enza & $32(89 \%)$ & $3(8 \%)$ & $1(3 \%)$ & $1(2 \%)$ & $39(93 \%)$ & $2(5 \%)$ & $24(59 \%)$ & $16(39 \%)$ & $1(2 \%)$ \\
\hline Total & $101(88 \%)$ & $10(9 \%)$ & $4(4 \%)$ & $8(6 \%)$ & $112(89 \%)$ & $6(5 \%)$ & $73(59 \%)$ & $45(36 \%)$ & $6(5 \%)$ \\
\hline$P$-value & & 0.76 & & & 0.065 & & & 0.53 & \\
\hline
\end{tabular}

AA, abiraterone acetate; Enza, enzalutamide; Chemo, chemotherapy.

had had prior chemotherapy. Narcotic analgesics use was $40 \%$ at baseline. Approximately half $(51.4 \%)$ of all eligible subjects in the study received all six planned doses of radium-223. The most common reason for receiving fewer than six doses was death. The overall survival for the entire cohort was 15.7 months (95\% Confidence Interval: 13.0-22.5 months). In ALSYMPCA study, the median OS in the radium-223 treated patients was 14.9 months (vs. the 11.3 months in the control arm) which is very comparable to our cohort.

In keeping with published trial experience with radium-223, in our real word cohort too radium-223 therapy caused only mild cytopenias (Table II toxicity). Anemia and thrombocytopenia were more common than neutropenia but were predominantly grade 1 or 2 and did not seem to differ by prior chemotherapy status. In terms of toxicity, the post-docetaxel group treated with radium-223 experienced more grade $3 / 4$ thrombocytopenia compared to placebo ( $9 \%$ vs. $3 \%$ ) while there was no statistical difference between treatment and placebo in the pre-docetaxel group, and neither were there any discernible differences in the frequencies of grade $3 / 4$ neutropenia and anemia versus placebo in either docetaxel-naive or post-docetaxel subsets. Baseline ECOG PS was in general good to excellent and largely maintained after completion of Radium-223 though some $(18.8 \%$; 25 / 133) patients experienced deterioration by the last radium dose.

In our cohort, $9 \%(11 / 119)$ of the patients with data available experienced an increase in WHO ladder score after the first/second cycles per reported pain scores (Fig. 1). This is termed "tumor flare" and an increase in the score indicates worsening pain. PSA declines by $50 \%$ or more from baseline occurred in $14 \%$ of the subjects for whom baseline and subsequent PSA values were available $(\mathrm{n}=128$; Fig. 2$)$. Serial ALP measurements were available in 70 subjects ( $49 \%$ ) and 35 of the $70(50 \%)$ had $25 \%$ or greater declines while
16 subjects $(23 \%)$ had reduction by $50 \%$ or more in their total ALP levels from baseline (Fig. 3). All but one subject with elevated ALP at baseline experienced declines with radium-223 therapy.

As no prognostic variables currently exist for benefit in patients receiving radium-223 therapy, we performed a univariate and multivariable analysis of clinical patient variables associated with overall survival (Table III). All pre-radium-223 clinical variables were independently associated with univariate overall survival except prior bisphosphonate use. In multivariate analysis, however, only elevated baseline ALP $(\geq 130 \mathrm{mg} / \mathrm{dl})$ and timing of radium-223 in the CRPC disease course in the context of prior abiraterone/enzalutamide and chemotherapy use were correlated with overall survival. Of note, the ALSYMPCA trial enrolled patients from June 2008 through February 2011 while abiraterone was FDA approved in 2011 though it was accessible through clinical trials prior to that. Response variables measured during radium-223 treatment were not found to be significantly

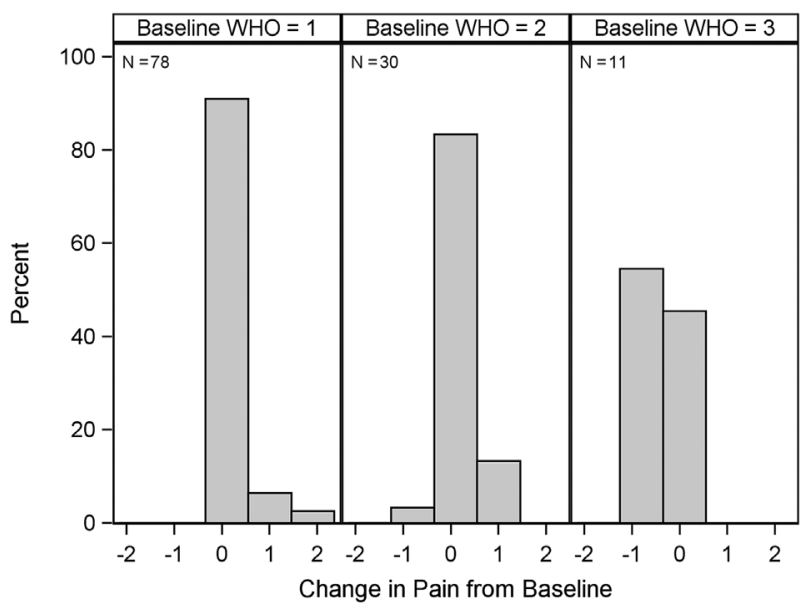

Fig. I. Greatest change in WHO pain ladder step stratified by baseline WHO pain ladder step. 


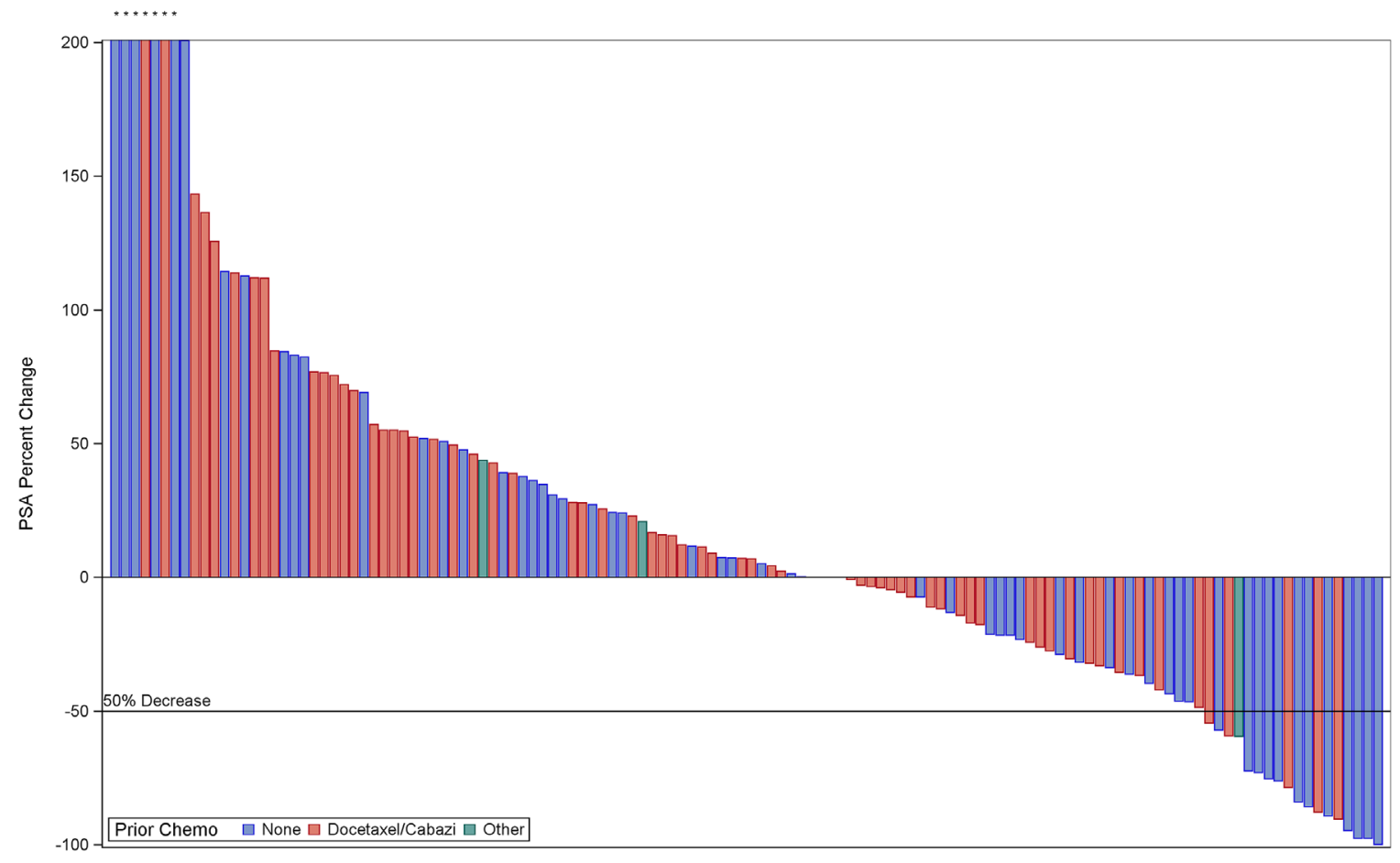

Fig. 2. Maximum PSA decline from baseline with radium-223 therapy $(N=128)$.

associated with overall survival. Overall survival by pre-treatment group is displayed in Figure 4. The number of radium-223 doses received was associated with ECOG performance status at baseline, extent of prior therapy and ALP elevation (Table IV).

A subgroup of $66(46 \%)$ patients had a baseline bone scan and was retrospectively analyzed for automated BSI assessment. No significant differences were observed in baseline characteristics of patients with bone scans versus without. Median baseline auto-BSI was 2.4 (range: 0.01-33.2). A smaller subset of patients $(\mathrm{n}=25)$ had bone scans available at both baseline and at 24-week treatment. Change in BSI was evaluated in these patients. Seventeen $(68 \%)$ of the 25 patients showed a decrease in auto-BSI from baseline. Consistent with previous studies, baseline BSI values were significantly associated with overall survival (Fig. 5). Due to the ad hoc BSI analysis on the available bone scans at treatment follow-up, the change in BSI is only reportable on 25 of the 66 patients with baseline bone scans. BSI declined in most of these patients who received six doses of radium-223. An illustrative example is shown in Figure 6.

\section{DISCUSSION}

With the inherent limitations of a retrospective chart review study, our multi-center cohort of mCRPC patients treated with radium-223 outside of trials is the largest group described to date with data measuring the real world impact of radium-223. The participating sites are cancer centers experienced in radium-223 therapy with a mix of academic and community practices.

Patients who had had no chemotherapy prior to radium had longer overall survival (OS) compared to those who had had chemotherapy. This likely reflects less advanced and less intractable disease. Consistent with this, more of those patients who received all six

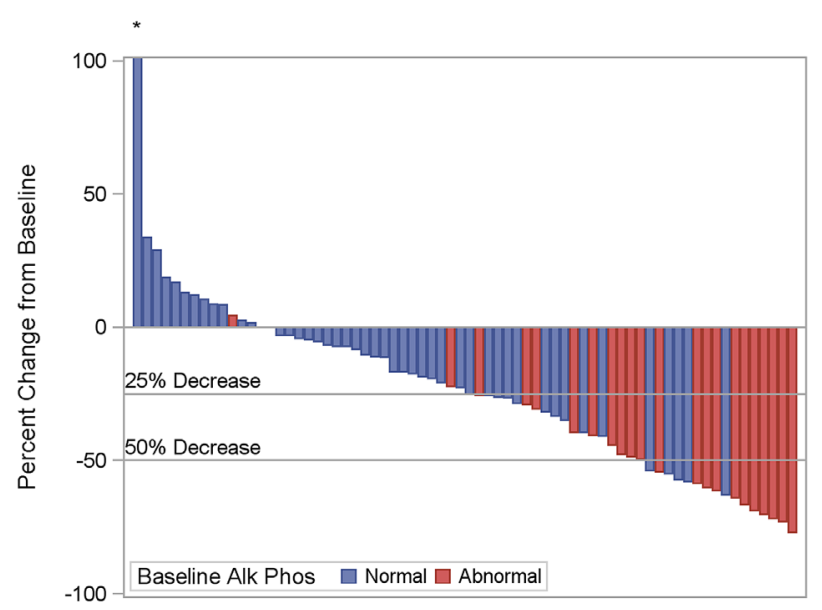

Fig. 3. Maximum decrease in alkaline phosphatase from baseline with radium-223 therapy $(\mathrm{N}=70)$. 
TABLE III. Overall Survival Models

\begin{tabular}{|c|c|c|c|c|}
\hline Clinical covariates prior to treatment & $\begin{array}{l}\text { Univariate models hazard } \\
\text { ratio }(95 \% \mathrm{CI})\end{array}$ & $P$-value & $\begin{array}{l}\text { Multivariable model hazard } \\
\text { ratio }(95 \% \mathrm{CI})\end{array}$ & $P$-value \\
\hline Age (per year increase) & $1.16(0.99,1.35)$ & 0.07 & & \\
\hline Height (per $10 \mathrm{~cm}$ increase) & $0.61(0.40,0.93)$ & 0.02 & & \\
\hline BMI (ref: $25-30) \mathrm{kg} / \mathrm{m}^{2}$ & & 0.04 & & \\
\hline$<25$ vs. $25-30$ & $1.51(0.77,2.96)$ & & & \\
\hline $30-35$ vs. $25-30$ & $0.40(0.16,1.02)$ & & & \\
\hline $35+$ vs. $25-30$ & $0.77(0.30,1.97)$ & & & \\
\hline ECOGPS $2 / 3$ vs. $1 / 2$ & $2.77(1.47,5.22)$ & 0.002 & & \\
\hline Baseline WHO pain score & & 0.03 & & \\
\hline 2 vs. 1 & $1.94(1.01,3.72)$ & & & \\
\hline 3 vs. 1 & $2.73(1.17,6.40)$ & & & \\
\hline Prior therapy & & 0.0006 & & 0.0008 \\
\hline None & Ref & & Ref & \\
\hline Abiraterone/enzalutamide & $0.93(0.25,3.45)$ & & $0.54(0.14,2.08)$ & \\
\hline Chemotherapy & $1.50(0.59,3.77)$ & & $1.77(0.70,4.48)$ & \\
\hline Chemo $+\mathrm{Abi} /$ enza & $4.05(1.87,8.79)$ & & $3.53(1.63,7.67)$ & \\
\hline \multicolumn{5}{|l|}{ Alkaline phosphatase at baseline } \\
\hline$\geq 130$ vs. $<130$ & $2.85(1.57,5.15)$ & 0.0006 & $3.13(1.67,5.86)$ & 0.0004 \\
\hline Log baseline PSA & $1.30(1.12,1.50)$ & 0.0004 & & \\
\hline \multicolumn{5}{|l|}{ Prior bisphosphonate/denosumab use } \\
\hline Yes vs. no & $1.18(0.65,2.14)$ & 0.60 & & \\
\hline \multicolumn{5}{|l|}{ Baseline BSI (log scale) } \\
\hline Study institution & - & 0.26 & & \\
\hline \multicolumn{5}{|l|}{ During therapy covariates } \\
\hline WHO pain ladder step change during therapy & & 0.47 & & \\
\hline Step increased vs. no change & $1.22(0.44,3.43)$ & & & \\
\hline Step decreased vs. no change & $2.05(0.63,6.67)$ & & & \\
\hline Hematologic toxicity & & 0.83 & & \\
\hline Grade $3 / 4$ vs. none & $0.53(0.06,4.65)$ & & & \\
\hline Grade $1 / 2$ vs. none & $0.54(0.07,4.01)$ & & & \\
\hline \multicolumn{5}{|l|}{$\begin{array}{l}25 \% \text { decrease in alkaline phosphatase from } \\
\text { baseline during rad therapy }\end{array}$} \\
\hline No vs. yes & $1.14(0.44,2.96)$ & 0.79 & & \\
\hline \multicolumn{5}{|l|}{ PSA response during Rad therapy? } \\
\hline Yes vs. no & $0.54(0.19,1.52)$ & 0.24 & & \\
\hline
\end{tabular}

planned radium doses had ECOG performance statuses of 0 or 1 versus those who received one or two doses.

Our analysis presents a few clear inferences. Pain relief from symptomatic bone metastases is a concrete benefit of radium-223 therapy. The decline in pain index and its individual components (VAS score and WHO ladder level) in most patients offers meaningful palliation from bone pain. There have been suggestions of a flare in pain, PSA or bone scan seen in up to $25 \%$ of pts with the initial doses of radium-223 in early studies akin to the LHRH flare effect, flare with ASIs or the taxane PSA surge [13,23-25]. The variability in analgesic use, missing data and small numbers with the first two cycles, probably account for the difference in reported frequency of the flare response with radium in our group of patients.

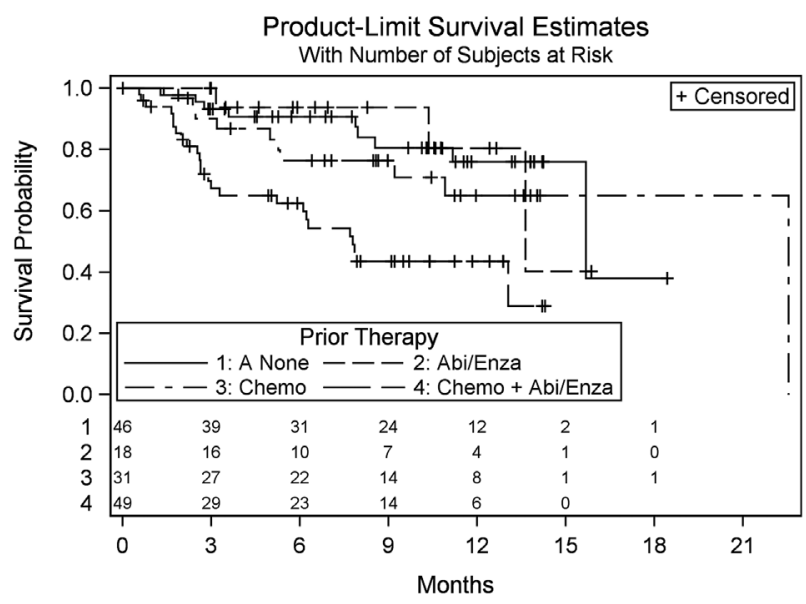

Fig. 4. Overall survival stratified by prior treatments received. 
TABLE IV. Association Between Clinical Variables and Number of Radium-223 Doses

\begin{tabular}{|c|c|c|c|c|}
\hline Baseline & $\begin{array}{l}1-2 \text { treatments of } \\
\text { radium- } 223\end{array}$ & $\begin{array}{c}3-4 \text { treatments of } \\
\text { radium-223 }\end{array}$ & $\begin{array}{c}5-6 \text { treatments of } \\
\text { radium-223 }\end{array}$ & $P$-value \\
\hline $\mathrm{N}$ & 39 & 24 & 81 & \\
\hline Mean age & $73.5(8.6)$ & $72.0(10.1)$ & $71.0(10.2)$ & 0.43 \\
\hline Height (per $10 \mathrm{~cm}$ increase) & $175.5(7.8)$ & $177.6(8.9)$ & $177.6(6.2)$ & 0.31 \\
\hline BMI & & & & 0.19 \\
\hline$<25$ & $13(33 \%)$ & $5(21 \%)$ & $20(25 \%)$ & \\
\hline $25-30$ & $15(38 \%)$ & $6(25 \%)$ & $23(28 \%)$ & \\
\hline $30-35$ & $7(19 \%)$ & $7(29 \%)$ & $24(30 \%)$ & \\
\hline $35+$ & $4(10 \%)$ & $6(25 \%)$ & $14(17 \%)$ & \\
\hline \multicolumn{5}{|l|}{ ECOG performance status } \\
\hline $0 / 1$ & $24(62 \%)$ & $21(88 \%)$ & $70(86 \%)$ & 0.005 \\
\hline $2 / 3$ & $15(38 \%)$ & $3(13 \%)$ & $11(14 \%)$ & \\
\hline PSA baseline median (IQR) & $188.7(42-517)$ & $172.5(58-470)$ & $20.7(4-97)$ & $<0.0001$ \\
\hline Prior treatment & & & & 0.0003 \\
\hline None & $7(18 \%)$ & $7(29 \%)$ & $32(40 \%)$ & \\
\hline Abiraterone/enzalutamide only & $4(10 \%)$ & $5(21 \%)$ & $9(11 \%)$ & \\
\hline Chemotherapy only & $5(13 \%)$ & $1(4 \%)$ & $25(31 \%)$ & \\
\hline Chemotherapy and abiraterone/enzalutamide & $23(59 \%)$ & $11(46 \%)$ & $15(19 \%)$ & \\
\hline Bisphosphonates use within 1 year of radium-223: Yes & $12(31 \%)$ & $9(38 \%)$ & $27(33 \%)$ & 0.88 \\
\hline Baseline WHO pain score & & & & 0.06 \\
\hline 1 & $22(56 \%)$ & $17(71 \%)$ & $58(72 \%)$ & \\
\hline 2 & $8(21 \%)$ & $7(29 \%)$ & $19(23 \%)$ & \\
\hline 3 & $9(23 \%)$ & $0(0 \%)$ & $4(5 \%)$ & \\
\hline $\begin{array}{l}\text { Alkaline phosphatase at baseline }(\mathrm{N}=89) \text { : Elevated (i.e., } \\
\geq 130)\end{array}$ & $22(56 \%)$ & $9(38 \%)$ & $25(31 \%)$ & 0.01 \\
\hline \multicolumn{5}{|l|}{ On-treatment changes } \\
\hline Toxicity & & & & \\
\hline None & $1(4 \%)$ & $2(10 \%)$ & $1(1 \%)$ & 0.43 \\
\hline Grade 1/2 & $21(81 \%)$ & $19(90 \%)$ & $68(86 \%)$ & \\
\hline Grade 3/4 & $4(15 \%)$ & 0 & $10(13 \%)$ & \\
\hline PSA response during radium-223 therapy $(\mathrm{N}=112)$ & $2(7 \%)$ & $1(5 \%)$ & $15(19 \%)$ & 0.06 \\
\hline $\begin{array}{l}25 \% \text { decrease in alkaline phosphatase from baseline } \\
\text { during radium-223 therapy }(\mathrm{N}=71) \text { : Yes }\end{array}$ & $4(57 \%)$ & $4(50 \%)$ & $27(49 \%)$ & 0.75 \\
\hline Change in pain level during therapy by VAS $(\mathrm{N}=117)$ & & & & 0.22 \\
\hline Pain decreased & $3(8 \%)$ & $0(0 \%)$ & $4(5 \%)$ & \\
\hline No change & $35(90 \%)$ & $22(92 \%)$ & $69(85 \%)$ & \\
\hline Pain increased & $1(3 \%)$ & $2(8 \%)$ & $8(10 \%)$ & \\
\hline Median survival $(95 \% \mathrm{CI})$ & $2.6(2.4-6.2)$ & 7.9 (5.2-NR) & 15.7 (15.7-22.5) & \\
\hline
\end{tabular}

PSA declines were noted in a minority of patients consistent with previously published data on impact of radium-223 therapy on PSA and its mechanism of action which is for the most part directed at the bone tumor microenvironment rather than at prostate cancer cells specifically. PSA values are therefore hard to interpret on radium-223 therapy and PSA changes should not direct radium-223 therapy decisions or duration.

ALP (total or bone-specific) has been explored as a potential biomarker for radium-223. In the early published experience, patients with elevated total ALP at baseline had robust declines but not those with normal ALP [13]. In an ad hoc analysis of ALP levels in ALSYMPCA patients, declines in ALP were correlated with prolonged survival. In our dataset, only half experienced declines but of those who had

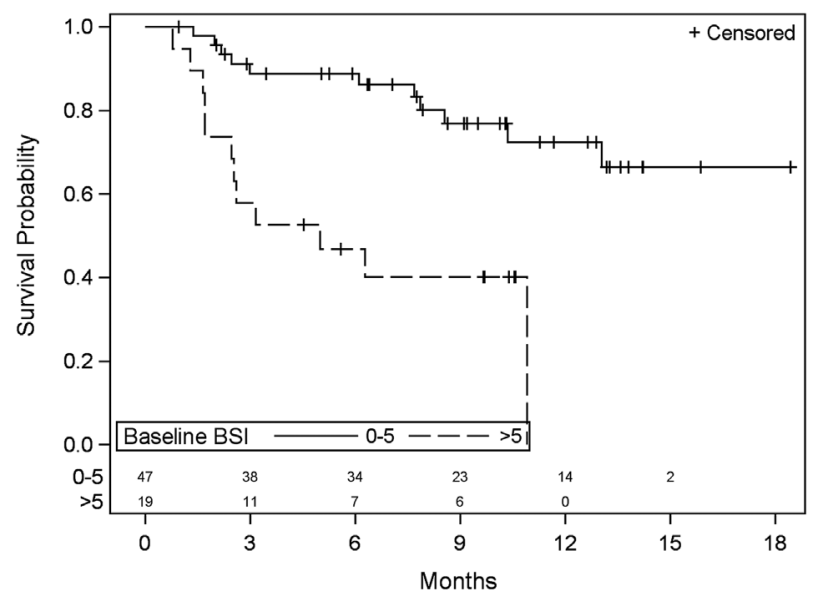

Fig. 5. Overall survival stratified by baseline $B S I(N=65)$. 


\section{Pre-therapy}

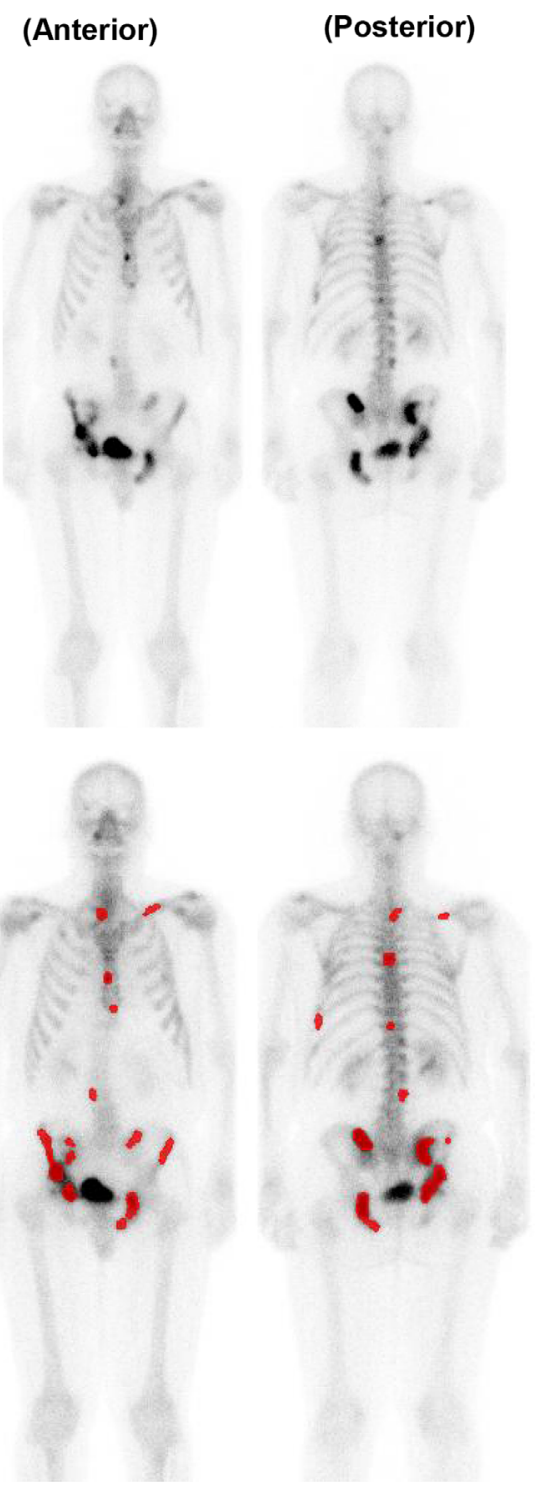

BSI: 2.65
Post-therapy

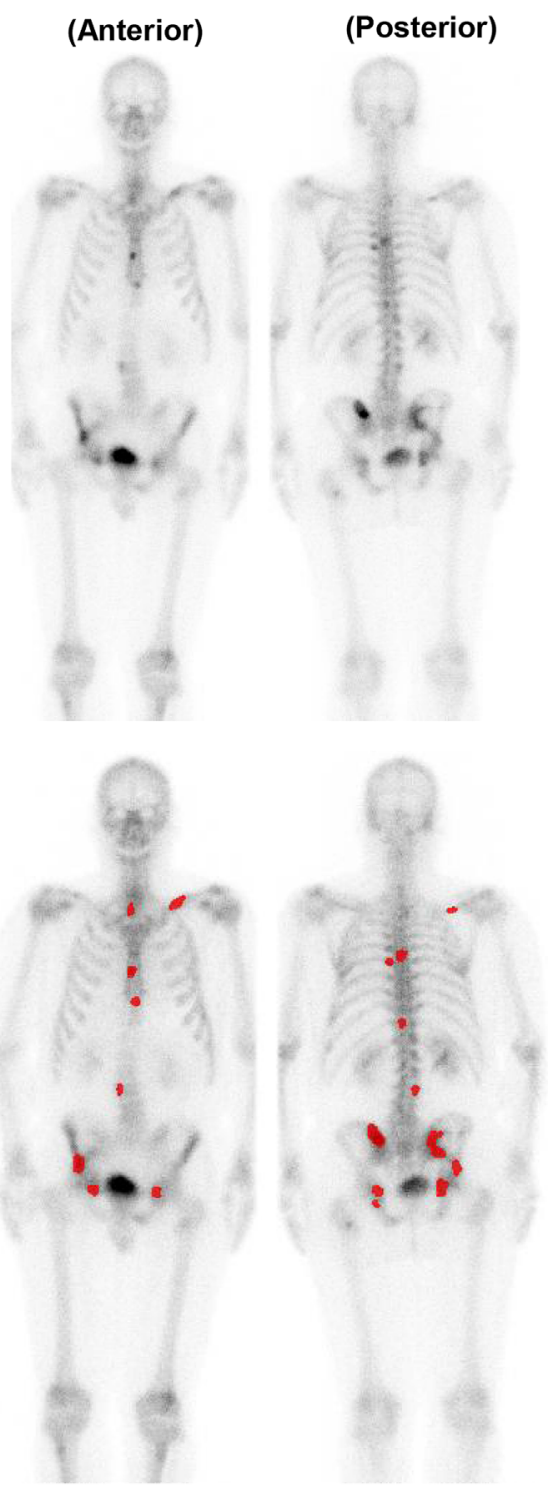

BSI: 1.40

Fig. 6. Illustrative on-treatment BSI change in a patient before and after six cycles of radium-223. The red color represents the hotspots detected by EXINI software and included in the BSI-assessment.

elevated values at baseline, all but one patient experienced a decrease. Unanswered questions remain: How specific a measure of tumor burden in bone is ALP in mCRPC patients? How predictive are changes in ALP? How does this marker perform in the large number of mCRPC patients whose total ALP is within the normal range at baseline? A panel of bone turnover markers may potentially better measure impact of radium-223 on bone and bone metastases.

Bone Scan Index (BSI) as a semi-quantitative assessment of bone scintigraphy has shown clinical validity as an imaging biomarker associated with overall survival in other contexts [26]. To our knowledge, this is the first study to explore the clinical context of BSI in metastatic prostate cancer patients treated with radium-223. Baseline BSI deserves to be further studied in future prospective trials of radium-223.

More than half of the patients in our cohort had received prior cytotoxic chemotherapy. Impact of prior chemotherapy on radium-223 toxicity and benefit was analyzed in patients on the ALSYMPCA trial in a pre-specified manner. Patients who had received docetaxel previously $(57 \%)$ as well as those docetaxel naive $(43 \%)$ derived an overall survival benefit from 
radium-223 with very similar hazard ratios and confidence intervals [20]. The bone marrow toxicity with radium-223 is remarkably modest and lends itself very well to combination therapy with agents from other classes including cytotoxic chemotherapy. Our post-radium follow-up data collection was limited and did not permit analysis of a possible radium223 impact on toxicity from subsequent therapies or incidence of secondary neoplasms.

An intriguing hypothesis based on the stated mechanism of action for radium-223 is that radium is ideally dosed on height, possibly a more accurate proxy for skeletal mass in a patient than body weight. If this hypothesis is true, obese patients are being over-treated currently (possibly experiencing more toxicities) and taller patients are being under-treated (possibly resulting in inferior clinical benefit and outcomes). In our univariate and multivariate analyses of our limited cohort, there is no evidence to support the former inference and no way to test the latter. The reasoning behind such a hypothesis may merit further prospective evaluation.

What emerges from our dataset is the importance of considering radium-223 early on in patients CRPC disease course where patients are more likely to receive all six planned cycles. The absence of a control arm limits our conclusions regarding the independent impact of radium-223 on the survival of our patients included in the study and it is probable that receipt of all six cycles is merely a surrogate for known good prognostic factors in CRPC such as better performance status. The lack of LDH values for a significant number of patients in this cohort made estimation of a predicted overall survival with tools such as the Halabi nomogram impossible but the OS was very comparable to data from radium-223 trials such as ALSYMPCA which also had docetaxel-untreated and treated CRPC patients.

Ongoing studies are exploring higher doses and longer courses of radium-223 treatment in prostate cancer (NCT02023697). One could safely surmise that utilizing radium-223 early on in the course of castration resistant prostate cancer before ECOG PS declines to two or worse is a reasonable and effective strategy given that dose number is key to deriving maximal benefit. Post-radium chemotherapy could be expected to be unhampered given the mild and reversible myelosuppressive effect of radium but awaits further data. Assessment of long-term complications such as secondary malignancies and if they are heightened by early radium-223 use deserves long-term prospective studies. Ongoing clinical trials are examining combinations of radium-223 with ASIs and no doubt, these will refine the role of radium-223 in the quickly burgeoning options for treatment of CRPC.

\section{CONCLUSIONS}

In this multisite retrospective study, patients who received radium-223 in CRPC prior to cytotoxic chemotherapy had longer survival as did those with elevated serum ALP. Radium-223 therapy is well tolerated in routine clinical practice with most patients experiencing declines in pain scores and BSI.

\section{CONFLICTS OF INTEREST}

Drs. Ajjai Alva, Evan Yu, Jorge Ramos, Saby George, and Ms. Stephanie Daignault have received research funding to their respective institutions from Bayer. Dr. Yu and Dr. George have also received consulting honorariums from Bayer. Mr. Aseem Anand is a paid consultant for EXINI Diagnostics. None of the other authors report any potential conflicts of interest.

\section{ACKNOWLEDGMENT}

This work was funded by Bayer Pharmaceuticals.

\section{REFERENCES}

1. American Cancer Society: Cancer Facts and Figures 2015. Atlanta GACS, 2015. Available online at http://www.cancer. org/acs/groups/content/@editorial/documents/document/ acspc-044552.pdf Last accessed January 7, 2015.

2. Debes JD, Tindall DJ. Mechanisms of androgen-refractory prostate cancer. N Engl J Med 2004;351:1488-1490.

3. Petrylak DP, Tangen CM, Hussain MH, Lara PN, Jr., Jones JA, Taplin ME, Burch PA, Berry D, Moinpour C, Kohli M, Benson MC, Small EJ, Raghavan D, Crawford ED. Docetaxel and estramustine compared with mitoxantrone and prednisone for advanced refractory prostate cancer. $\mathrm{N}$ Engl J Med 2004;351:1513-1520.

4. Tannock IF, de Wit R, Berry WR, Horti J, Pluzanska A, Chi KN, Oudard S, Theodore C, James ND, Turesson I, Rosenthal MA, Eisenberger MA. Docetaxel plus prednisone or mitoxantrone plus prednisone for advanced prostate cancer. N Engl J Med 2004;351:1502-1512.

5. de Bono JS, Oudard S, Ozguroglu M, Hansen S, Machiels JP, Kocak I, Gravis G, Bodrogi I, Mackenzie MJ, Shen L, Roessner M, Gupta S, Sartor AO. Prednisone plus cabazitaxel or mitoxantrone for metastatic castration-resistant prostate cancer progressing after docetaxel treatment: A randomised open-label trial. Lancet 2010;376:1147-1154.

6. de Bono JS, Logothetis CJ, Molina A, Fizazi K, North S, Chu L, Chi KN, Jones RJ, Goodman OB, Jr., Saad F, Staffurth JN, Mainwaring P, Harland S, Flaig TW, Hutson TE, Cheng T, Patterson H, Hainsworth JD, Ryan CJ, Sternberg CN, Ellard SL, Flechon A, Saleh M, Scholz M, Efstathiou E, Zivi A, Bianchini D, Loriot Y, Chieffo N, Kheoh T, Haqq CM, Scher HI. Abiraterone and increased survival in metastatic prostate cancer. N Engl J Med 2011;364:1995-2005.

7. Ryan CJ, Smith MR, de Bono JS, Molina A, Logothetis CJ, de Souza P, Fizazi K, Mainwaring P, Piulats JM, Ng S, Carles J, 
Mulders PF, Basch E, Small EJ, Saad F, Schrijvers D, Van Poppel H, Mukherjee SD, Suttmann H, Gerritsen WR, Flaig TW, George DJ, Yu EY, Efstathiou E, Pantuck A, Winquist E, Higano CS, Taplin ME, Park Y, Kheoh T, Griffin T, Scher HI, Rathkopf DE. Abiraterone in metastatic prostate cancer without previous chemotherapy. N Engl J Med 2013;368: 138-148.

8. Scher HI, Fizazi K, Saad F, Taplin ME, Sternberg CN, Miller K, de Wit R, Mulders P, Chi KN, Shore ND, Armstrong AJ, Flaig TW, Flechon A, Mainwaring P, Fleming M, Hainsworth JD, Hirmand M, Selby B, Seely L, de Bono JS. Increased survival with enzalutamide in prostate cancer after chemotherapy. N Engl J Med 2012;367:1187-1197.

9. Beer TM, Tombal B. Enzalutamide in metastatic prostate cancer before chemotherapy. N Engl J Med 2014;371:1755-1756.

10. Kantoff PW, Higano CS, Shore ND, Berger ER, Small EJ, Penson DF, Redfern CH, Ferrari AC, Dreicer R, Sims RB, Xu Y, Frohlich MW, Schellhammer PF. Sipuleucel-T immunotherapy for castration-resistant prostate cancer. N Engl J Med 2010;363:411-422.

11. Parker C, Sartor O. Radium-223 in prostate cancer. N Engl J Med 2013;369:1659-1660.

12. Bruland OS, Nilsson S, Fisher DR, Larsen RH. High-linear energy transfer irradiation targeted to skeletal metastases by the alpha-emitter 223Ra: Adjuvant or alternative to conventional modalities? Clin Cancer Res 2006;12:6250s-6257s.

13. Nilsson S, Larsen RH, Fossa SD, Balteskard L, Borch KW, Westlin JE, Salberg G, Bruland OS. First clinical experience with alpha-emitting radium-223 in the treatment of skeletal metastases. Clin Cancer Res 2005;11:4451-4459.

14. Nilsson S, Franzen L, Parker C, Tyrrell C, Blom R, Tennvall J, Lennernas B, Petersson U, Johannessen DC, Sokal M, Pigott K, Yachnin J, Garkavij M, Strang P, Harmenberg J, Bolstad B, Bruland OS. Bone-targeted radium-223 in symptomatic, hormone-refractory prostate cancer: A randomised, multicentre, placebo-controlled phase II study. Lancet Oncol 2007;8:587-594.

15. Nilsson S, Strang P, Aksnes AK, Franzen L, Olivier P, Pecking A, Staffurth J, Vasanthan S, Andersson C, Bruland OS. A randomized, dose-response, multicenter phase II study of radium-223 chloride for the palliation of painful bone metastases in patients with castration-resistant prostate cancer. Eur J Cancer 2012;48:678-686.

16. Nilsson S, Franzen L, Parker C, Tyrrell C, Blom R, Tennvall J, Lennernas B, Petersson U, Johannessen DC, Sokal M, Pigott K, O'Bryan-Tear CG, Thuresson M, Bolstad B, Bruland OS. Twoyear survival follow-up of the randomized, double-blind, placebo-controlled phase II study of radium-223 chloride in patients with castration-resistant prostate cancer and bone metastases. Clin Genitourin Cancer 2013;11:20-26.

17. http://www.who.int/cancer/palliative/painladder/en/
18. Parker CC, Pascoe S, Chodacki A, O'Sullivan JM, Germa JR, O'Bryan-Tear CG, Haider T, Hoskin P. A randomized, double-blind, dose-finding, multicenter, phase 2 study of radium chloride ( $\mathrm{Ra} 223$ ) in patients with bone metastases and castration-resistant prostate cancer. Eur Urol 2013;63: 189-197.

19. Sartor O, Coleman R, Nilsson S, Heinrich D, Helle SI, O'Sullivan JM, Fossa SD, Chodacki A, Wiechno P, Logue J, Widmark A, Johannessen DC, Hoskin P, James ND, Solberg A, Syndikus I, Vogelzang NJ, O'Bryan-Tear CG, Shan M, Bruland OS, Parker C. Effect of radium-223 dichloride on symptomatic skeletal events in patients with castration-resistant prostate cancer and bone metastases: Results from a phase 3, double-blind, randomised trial. Lancet Oncol 2014;15:738-746.

20. Hoskin P, Sartor O, O'Sullivan JM, Johannessen DC, Helle SI, Logue J, Bottomley D, Nilsson S, Vogelzang NJ, Fang F, Wahba M, Aksnes AK, Parker C. Efficacy and safety of radium-223 dichloride in patients with castration-resistant prostate cancer and symptomatic bone metastases, with or without previous docetaxel use: A prespecified subgroup analysis from the randomised, double-blind, phase 3 ALSYMPCA trial. Lancet Oncol 2014;15:1397-1406.

21. FDA approves radiopharmaceutical for metastatic prostate cancer. Cancer Discov 3:OF1, 2013.

22. Anand A, Morris MJ, Kaboteh R, Bath L, Sadik M, Gjertsson $P$, Lomsky M, Edenbrandt L, Minarik D, Bjartell A. Analytic validation of the automated bone scan index as an imaging biomarker to standardize quantitative changes in bone scans of patients with metastatic prostate cancer. J Nucl Med 2016;57: $41-45$.

23. Thuret R, Massard C, Gross-Goupil M, Escudier B, Di Palma M, Bossi A, de Crevoisier R, Chauchereau A, Fizazi K. The postchemotherapy PSA surge syndrome. Ann Oncol 2008;19: 1308-1311.

24. Ryan CJ, Shah S, Efstathiou E, Smith MR, Taplin ME, Bubley GJ, Logothetis CJ, Kheoh T, Kilian C, Haqq CM, Molina A, Small EJ. Phase II study of abiraterone acetate in chemotherapy-naive metastatic castration-resistant prostate cancer displaying bone flare discordant with serologic response. Clin Cancer Res 2011;17:4854-4861.

25. Pieczonka CBM, Mouravieva V, Albala D, Mouraviev V, Mariados: N. Initial experience of radium-223 treatment for metastatic castrate resistant prostate cancer in community setting. J Clin Oncol 2014;32: (suppl; abstr e16106).

26. Anand A, Morris MJ, Larson SM, Minarik D, Josefsson A, Helgstrand JT, Oturai PS, Edenbrandt L, Roder MA, Bjartell A. Automated Bone Scan Index as a quantitative imaging biomarker in metastatic castration-resistant prostate cancer patients being treated with enzalutamide. EJNMMI Res 2016;6:23. 